\title{
19q13.11 microdeletion syndrome
}

INSERM

\section{Source}

INSERM. (1999). Orphanet: an online rare disease and orphan drug data base. 19q13.11 microdeletion syndrome. ORPHA:217346

The 19q13.11 microdeletion is characterized by several major features including pre and postnatal growth retardation, slender habitus, severe postnatal feeding difficulties, microcephaly, intellectual deficit with speech disturbance, hypospadias and ectodermal dysplasia presented by scalp aplasia, thin and sparse hair, eyebrows and eyelashes, thin and dry skin and dysplasic nails. 